BNL-62043

AD/RHIC-135

Informal Report

\title{
Acquisition of Reliable Vacuum Hardware for Large Accelerator Systems
}

Kimo M. Welch

October 1995

\section{R H I C P R O J E C T}

Brookhaven National Laboratory

Associated Universities, Inc.

Upton, NY 11973 



\title{
ACQUISITION OF RELIABLE VACUUM HARDWARE
}

\author{
FOR LARGE ACCELERATOR SYSTEMS*
}

\author{
Kimo M. Welch
}

September 6, 1995

\begin{abstract}
Credible and effective communications prove to be the major challenge in the acquisition of reliable vacuum hardware. Technical competence is necessary but not sufficient. We must effectively communicate with management, sponsoring agencies, project organizations, service groups, staff and with vendors. Most of Deming's 14 quality assurance tenants relate to creating an enlightened environment of good communications. All projects progress along six distinct, closely coupled, dynamic phases. All six phases are in a state of perpetual change. These phases and their elements are discussed, with emphasis given to the acquisition phase and its related vocabulary. Large projects require great clarity and rigor as poor communications can be costly. For rigor to be cost effective, it can't be pedantic. Clarity thrives best in a low-risk, team environment.
\end{abstract}

*Presented at the 13th International Vacuum Congress, \& 9th International Conference on Solid Surfaces, Yokohama, Japan, September 1995. 


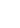




\section{INTRODUCTION}

There is no single or correct way to achieve reliability in any system. However, there are numerous incorrect ways of attempting to do so. The material presented represents a perception of some important elements which might lead to success in achieving reliability. It is based on experience gained over a 40 -year period filled with both successes and failures in product development, engineering, operations and project management. The views herein, and some are controversial, are not necessarily the views of BNL management or the DoE.

The word reliability is used synonymously with the word quality, and both synonymously with the word value. There must be appropriate return on investment in measures taken to achieve reliability, or the cost of that reliability will exceed the value of the end product. Suggested reading for those interested in reliability, or quality, or value, might start with a recent publication of Dobyns and Crawford-Mason. ${ }^{1}$ Though sprinkled with frequent sophomoric attempts at humor, this book is of considerable value in summarizing the tenants of W.E. Deming's QA philosophy, and the discussion of QA misconceptions of many in their quest for quality. Those interested in the elements of project management might find the recent work of Rich and Janos both interesting and entertaining. ${ }^{2}$ This book is inspiring in that it relates major project accomplishments which can be achieved through a concerted team effort.

The very scope of the Relativistic Heavy Ion Collider (RHIC), presently under construction at $\mathrm{BNL}$ and described elsewhere, ${ }^{3,4}$ presents unique communications challenges. A schematic representation of the RHIC is shown in Fig. 1. To assure acceptable beam storage lifetimes and minimize emittance growth of the counter-rotating beams in the $3.8 \mathrm{~km}$ rings, all of the RHIC warm-bore systems must operate at $\leq 5 \times 10^{-10}$ Torr $\mathrm{H}_{2}$ equivalent, whereas the cold-bore systems, comprising $83 \%$ of each ring, must operate at $\leq 10^{-11}$ Torr $\mathrm{H}_{2}$ equivalent pressure. The project scope, and breadth and diversity of talent being brought to bear in the endeavor require refined skills in communication, coordination and cooperation (called $\mathrm{C}^{3}$ hereafter). ${ }^{5}$

\section{GENERAL COMMENTS ON PLANNING}

I have never audited or participated in a project or experiment which was overplanned. I have been involved in and audited many projects and experiments which for lack of sufficient planning failed or had to be repeated. Obviously, the planning process takes place in phases, starting with very crude estimates or tests of fiscal and technical viability, and progressing into more refined states in time. It is critical that those who will 
be involved in executing the plan participate as early as possible in formulating the plan. Knowledge of imposed fiscal and technical boundary conditions on the part of those formulating the plan lends purpose and commitment in their execution of the plan.

First and foremost, one must recognize that a plan is a living document which will change in time. If a plan is perfect and need not ever be modified it is probably fiscally bloated and does not fully exploit or stretch the resources brought to bare in its execution. On the other hand, if a plan is unrealistically optimistic, those tasked with its execution will very quickly know this and become overwhelmed into inaction. Lastly, a plan can be a best effort endeavor, be publicized as such, and be very enjoyable in its execution, no matter how overly ambitious it is, in a highly motivated team environment.

It is also most important to clearly define and have a project-wide understanding of the objectives of the plan. That is, the plan does not manage the program, any more than a road-map drives an automobile from one place to another. A road-map defines a course to be followed. It is also used to determine where you are along the journey. It must not be obtrusive or costly to use, and it must not excessively distract the attention of the driver. However, the plan can't be discretionary at functional levels, and must be under a form of configuration control.

Sophisticated software exists for planning very complex projects. However, the project must guard against over-exploiting this sophistication at the expense of resource dilution. The larger the project, the greater the number of staff who must be involved in creating the plan, and in reporting progress they are achieving against the plan. It is management's responsibility to make sure that the plan does not grow, and take on a life of its own to the distraction of the goal of the plan. An occasional management review of the Plan Objective Specification should help avoid this pitfall. But, let us get on with the form and implementation of $\mathrm{C}^{3}$.

\section{TOOLS FOR PROJECT $\mathrm{C}^{3}$}

Three $\mathrm{C}^{3}$ tools will be herein discussed. They include the Vacuum Involvement Matrix, Project Cycle Template, and Design Cycle Flow Chart. They are not offered as project panaceas, but as tools that might serve as $C^{3}$ vehicles throughout a project.

\section{A. VACUUM INVOLVEMENT MATRIX}

Approximately 12,000 pieces of vacuum equipment (i.e., hardware, electronics and software) must be either built or purchased and then installed in the collider. The users of some this equipment are also developing and obtaining their own hardware, which 
includes: experimental detectors; RF systems; beam components such as kickers, Lambertson magnets, beam dumps, polarimeters, and collimators; superconducting magnets; cryostats; beam transport lines leading into the RHIC; beam instrumentation, etc., all interfacing with the RHIC vacuum systems. Assuming resident technical competence, the only assurance one has of effectively meeting the system requirements is by establishing good $\mathrm{C}^{3}$. (Incidentally, the term healthy competition within a project or. team is an oxymoron.)

The breadth of involvement made evident the need of a $C^{3}$ vehicle for use throughout the RHIC project. This is termed a Vacuum Involvement Matrix, and is shown in Fig. 2. It was prepared and disseminated early in the RHIC development phase. It lists most of the systems which must interface with, or may have either a favorable or deleterious impact on the quality and reliability of the RHIC vacuum systems. It attempts to define the minimum vacuum equipment requirements of the machine. It is used internal to the vacuum group. But more importantly, it was widely disseminated throughout the rest of the project. Note that this is not a control tool, but rather a tool to $C^{3}$ with the numerous divisions and organizations which impact on the RHIC vacuum.

\section{B. THE PROJECT CYCLE TEMPLATE}

A Project Cycle Template is expressly used to establish $\mathrm{C}^{3}$ expectations within the vacuum section. This template is shown in Table I. It is divided into the six project phases: i) Purpose \& Definition; ii) Planning; iii) Proposal; iv) Design; v) Acquisition of Hardware \& Software; and, vi) Installation \& Final Test. The elements of each phase offer insight into the real scope of team membership. One simply asks: "With whom must we $C^{3}$ in order to fulfill any one of the elements?" In answering this question you have defined the team members on whom you must rely for project success.

A project is herein defined as both a high-level and low-level endeavor. For example, constructing the RHIC is by any interpretation a major or high-level project, whereas the acquisition of a complex piece of equipment can constitute a low-level project.

We all too often take for granted interests and talents of those with whom we work. We use words in our discussions which have one meaning to us, and perhaps another meaning to others. More often than not, we hear what we want to hear. Therefore, it is of the utmost importance that one establish a clear definition of expectations of the team players. This clarity must exist between you and your immediate superior, you and your subordinates, and you and the rest of the project team. At times ambiguity regarding expectations is unavoidable, but it is never desirable. This is particularly so when expectations of one person are at odds with those of another. 
One does not purchase reliability. Reliability stems from each team player having an acute sense of the importance of $\mathrm{C}^{3}$, and then bringing their skills to bear in fulfilling their responsibilities. They must know what is expected of them, and then be motivated to fulfill the team's expectations. When this happens the reliability of the work product inherently increases.

Note that the template, similar to the project plan, is a road map. It points out landmarks along the journey which may or may not merit consideration. It differs from the plan in that many elements within it may be discretionary, depending on the magnitude of the project, whereas schedule deadlines and costs within the plan are non discretionary. Elements of some of the template phases will be discussed.

\section{OBJECTIVE SPECIFICATIONS}

An Objective Specification (OS), the first task of Phase I of the Project Cycle Template, is used as a $\mathrm{C}^{3}$ vehicle for purposes including: i) freezing definitions of equipment attributes within the section; ii) to alert Contracts and Procurement (i.e., Purchasing) of the variety and quantities of equipment to be purchased; iii) for dissemination to vendors at prebid conferences or during their frequent visits to your facility; and, iv) for legal notification of your organization's intent to purchase equipment, when such is required by law. An equipment OS should comprise no more than two or three sentences. It is not a Technical Specification, but rather a general description of attributes of the equipment and the quantities to be purchased. Ideally, those assigned to the project are intimately familiar with their respective responsibilities, and helped formulate Objective Specifications (OS) for their respective equipment.

Writing an OS for each section acquisition avoids the problem of equipment objectives drifting off course in the template gestation cycle. Regarding $\mathrm{C}^{3}$ with Purchasing, it has been my experience over the years that most Purchasing organizations perform magnificently when they are recognized as crucial members of the team. If one establishes $\mathrm{C}^{3}$ relationships directly with staff of Purchasing, rather than by dealing with them through the mail, the overall performance of the team will be enhanced.

It is important to provide vendors with early copies of OSs. A vendor prebid conference serves as a good forum for doing this. There are literally a dozen good reasons for convening a vendor prebid conference. However, in brief the conference serves to: i) provide vendors with an over-view of the entire project; ii) discuss details of equipment highlighted by each OS; iii) alert vendors of the intent regarding types, quantities, and probable schedules for acquisition of the equipment; iv) answer questions in an open forum; and, v) invite possible alternate proposals. Some 65 vendor 
representatives attended the RHIC vacuum prebid conference. Attempting to accomplish the above on an individual vendor basis would have resulted in a costly dilution of effort. If there are $\sim 150$ part numbers and 65 vendors, there could be almost 10,000 individual vendor encounters, each of which represents a hidden cost transaction. A hidden transaction is time spent that did not add value to the work product. This does not mean that vendors are unwelcome to individually call and discuss their wares. The OSs and prebid conference merely afford assurances that both you and the vendors will be better prepared, and later $\mathrm{C}^{3}$ exchanges will be more productive.

\section{THE WORK BREAKDOWN SCHEDULE}

The WBS (work breakdown schedule), an element of Phase II, is used to tabulate costs of hardware, electronics and software which must be acquired, installed and tested. It is the keystone of all future planning and project activities. The WBS includes quantities and estimated costs of equipment, and the manpower loading needed to obtain and test that equipment, by whatever means. The term schedule in WBS, is a misnomer. The WBS is strictly a tabular accounting of all costs, and it lacks schedule information. It is the WBS data that are used to schedule, load and level manpower requirements. Manpower loading is defined as estimating the number of hours and type of skill involved to complete an assingment, whereas manpower leveling means scheduling assignments so that all of the team is gainfully employed most of the time. Having a WBS and schedule, makes it possible to identify and partition specific assignments.

Formalizing a WBS and manpower loading and leveling the project is an iterative process as costs and schedules are dictated by the over-all project objectives, and one usually does not know the outcome prior to this work. Once WBS costs and schedules are in concert with the over-all project, the section plan is then integrated into a master project schedule.

\section{THE DESIGN CYCLE}

Activities in Phase III, the Design Cycle, depend on make/buy intents. That is, do you intend to build the equipment at the site, or purchase the equipment. The RHIC management policy is to purchase all equipment which can be manufactured by industry unless there are overriding technical or cost considerations. Considerations dictating that we construct the equipment at BNL are rare. Nevertheless all elements of the design cycle must be considered even in the buy process. These elements are shown in Fig. 3, the design cycle flow chart. 
It is clear from the elements or steps shown in this chart that it is impossible to decouple any one of the Project Cycle Template phases from the other related phases. For example, if the equipment is to be built on site, many of the elements of the Acquisition Phase must come into play. There must be Technical Specifications and Acceptance Tests Procedures (ATPs) associated with on-site construction of the equipment. If costs of initial designs prove prohibitive, whether the equipment is built on site or purchased, the equipment project may have to return to the either the Proposal or Planning Phase. If the installation and use of the equipment involves safety or ALARA considerations, even if it is purchased, the designs (or documentation) must go through the appropriate design reviews. (ALARA is an acronym for giving consideration in the design and operation of reactors or accelerators to assure that staff exposure to radiation is as low as reasonably achievable.)

\section{THE ACQUISITION PHASE}

\section{A. A FEW TECHNICAL REQUIREMENTS}

Technical requirements which we call out in specifications for hardware typically have to do with meeting form, fit and function. The component material is often defined,as well as its cleanliness, and the need for radiation immunity and bakeability where applicable.

Without exception, we specify that cutting fluids be water-soluble and free of sulfur or silicone. Also, we require that component piece parts be cleaned prior to welding, and that they be leak checked immediately after welding. Experience has shown us that: $i)$ the quality of welds is impacted in a major way by the cleanliness of parts during welding; ii) it is not possible to achieve the required $100 \%$ penetration welds, when welding from the exterior, when parts are not cleaned, even with a good argon purge; and, iii) cleaning the parts after welding and prior to leak checking can plug leaks, and mask the existence of defective welds.

All UHV parts are baked at $300 \mathrm{C}$ as a first step in an incoming inspection process. This procedure has disclosed leaks in a variety of parts which were probably cleaned by the vendor after welding. Because of the significant value added after receipt, all RHIC vacuum hardware is leak checked prior to installation. For example, a typical RHIC sextant comprises a continuous $480 \mathrm{~m}$ cryostat housing many superconducting magnets. A defective $\mathrm{HV}$ valve, no matter how inexpensive it might be, would cause considerable difficulty if it was discovered after extended pumping on a $480 \mathrm{~m}$ cryostat. Warm-bore system components must undergo in situ bakeout. Similar arguments apply to the 
replacement of leaking UHV components after installation and bakeout. Of course, all equipment is sufficiently exercised on receipt to weed out functional defects.

All electronics are exercised and burned in for eight hours on dummy loads on initial receipt. All electronics are controlled through RS-485 data buses. Therefore, simple and inexpensive software programs make it possible to perform this burn-in completely unattended. Because of the high humidity and dusty locations housing some of the electronics, all high voltage and low current printed circuit boards in vacuum instrumentation power supplies are conformally coated. Conformal coating affords some immunity to voltage breakdown and leakage currents. These and other product-specific provisions define some aspects of the RHIC vacuum group reliability program.

\section{B. QUANTIFYING RELIABILITY REQUIREMENTS}

There are instances when researching certain technical features about a product is too formidable. Also, i) some vendors might not want to prematurely divulge information which is company proprietary; ii) whereas, if the customer included these features in an RFP, they might be accused of submitting requirements which lock out other competition. An RFP (request for proposal) is the vehicle used to solicit proposals for equipment which the customer may find difficulty in satisfactorily quantifying or specifying.

A properly administrated RFP is very time consuming and is therefore used with great discretion. Every attempt is made to make evaluation of the RFP responses as objective as possible. Comprehensive SoWs, Tech. Specs. and SCDs must still be prepared. These are called baseline requirements. The qualities by which an RFP might be judged are included in Table II. In efforts to quantify the method by which reliability might be assessed, the following unit life cycle cost equation was formulated, and used to weight responses:

$$
u l c c=\Re \times[(U P / n)+(\$ X)+(\$ Y) \times((5-n) / 5)]+M E C / m
$$

where, $\Re=40,000 \mathrm{~h} / \mathrm{DMTBF}$,

$\mathrm{DMTBF}=$ the demonstrated system mean time between failure,

$U P=$ the average unit price, including nonrecurring engineering,

$n=$ the number of years warranty,

$\$ X=$ the cost of replacing a system in the RHIC,

$\$ Y=$ the cost of servicing a system in the shop,

$M E C=$ maintenance equipment (requested) costs,

$m=$ the number of units purchased. 
Estimated values of $\$ X$ and $\$ Y$ are provided the bidders when issuing the RFP for the given equipment. Obviously, the goal of the project engineer and vendor is to minimize the $u l c c$. The vendor is challenged to provide equipment with a large DMTBF, minimize MEC, and offer a favorable equipment warranty. The project engineer is challenged to configure the technical portion of the RFP in such a way to $C^{3}$ with the vendor with the greatest clarity, and minimize costs associated with replacing and servicing the equipment.

\section{QUALITY ASSURANCE GUIDELINES}

Several decades of experience has led me to believe that QA is viewed by most as a necessary evil. Many times when a customer purchases equipment from vendor, QA considerations are totally disregarded. In as many instances, the unfortunate vendor is completely inundated with boiler plate, documentation and unnecessary and costly busy work. In both instances, customers do this either out of ignorance or laziness, and the vendors certainly don't perceive of themselves as part of the team.

Vendor QA programs often comprise the formality of volume checking for flaws in workmanship or, in some instances, making outward appearances of satisfying the requirements of the customer. ${ }^{6}$ Many managers fill QA positions in their organizations with staff whom they perceive as marginally accomplished engineers. They staff with people who are expected to inspect, audit and create and maintain a paper trail, perceive this as QA, and then are disappointed when the quality or reliability of the product suffers. This management philosophy is self-fulfilling as profits suffer because of the lack of progressive QA programs in the organization. Quality assurance is everyone's responsibility in the organization, and it must start with the education of managers, who then must become the organizational champions of quality.

There are some simple guidelines which we attempt to remember when specifying QA requirements of specific equipment. It helps when configuring your own guidelines to place yourself in the vendor's position. Early in the RHIC project, vacuum section staff members gathered and hammered out some QA guidelines which would be applicable to all hardware, electronics and software acquisitions. These guidelines are divided into Operating Principles and Technical Requirements which are invoked with each acquisition. The Operating Principles are outlined in Table III.

Brookhaven National Laboratory has prepared a document, BNL-QA-101, which comprises an excellent summary of all conceivable technical QA requirements which might be applicable to an acquisition. The first page of the four-page document lists some general requirements, whereas the remaining pages comprise provisions which are 
optional to the project engineer. Rather than diluting our efforts by thinking through QA requirements, and risking oversights each time requisitions are written for equipment, the vacuum section staff constructed a generic table of requirements which the team collectively agreed should be applicable to all our acquisitions. Through time these guidelines have been progressively simplified through a continual revision process, aimed at reducing costs to BNL. This half-page table is included in the Tech. Spec. or SoW accompanying each requisition. We have never found it necessary to add provisions to the table, but in time we have eliminated provisions which we found did not add value to the equipment. Editing of this table is also collectively done by the team.

\section{VENDOR LIAISON}

Prior to the issuance of an RFQ, BNL and specifically Purchasing, has an open-door policy regarding vendors visiting sections or divisions. This makes it possible for the vendors who diligently call on these organizations to know a great deal about BNL's requirements prior to issuance of a specific RFQ. (Some large companies actually prohibit these productive $\mathrm{C}^{3}$ exchanges.) However, once the RFQ is issued, the door is closed, and no further vendor dialogue may occur with the project engineer except through Purchasing.

If after issuance of the RFQ, changes are requested by a vendor in the SoW, Tech. Spec., or SCD, these requested changes constitute exceptions in scope to the contract. If a change request is allowed to one, it must be allowed to all vendors. Allowing exceptions to contract conditions can result in significant program delays. For example, 35 vendors requested to be on one particular equipment bidders list. When a request for waiver of a specific clause was made by one vendor, and it was agreed to, 34 other vendors had to be contacted, and the waiver also granted to them. It is to both the vendor's and BNL's advantage that equipment-specific $\mathrm{C}^{3}$ vendor dialogue occur early in the project cycle.

\section{CONCLUSIONS}

Examples have been given of only a few methods by which communications, coordination and cooperation may be enhanced in any project. The main thesis is that all individuals with whom one must interact in the project must be viewed as team members with whom there must be $\mathrm{C}^{3}$ exchanges. And, that operating with this enlightened approach alone will lead to enhancements in productivity and reliability. One of course must be mindful of the distinction between collegiality $v s$. good $\mathrm{C}^{3}$ exchange. The former may be the byproduct of the latter, but it is not a substitute for the latter. However, 
organizations which aren't working well usually evidence poor $\mathrm{C}^{3}$ problems, regardless of their configuration. Poor $\mathrm{C}^{3}$ in an organization may be an effect of personalities, rather than a cause of the problem. Therefore, as individuals, we are each challenged to act and be perceived as striving for good communications, coordination and cooperation with team members. These elements and technical competence assure project success.

\section{ACKNOWLEDGMENTS}

I wish to thank Dr. Satoshi Ozaki, the RHIC Project Director, the rest of RHIC management, and the Department of Energy for their support in our quest for $\mathrm{C}^{3}$. I wish to thank Mr. Jerry Einfalt who, over four decades helped educate me in many of the technical aspects of quality assurance. Lastly, I greatly appreciate the assistance of Loralie Smart in helping me obtain better organization and clarity in the preparation of this paper.

\section{REFERENCES}

1) L. Dobyns and C. Crawford-Mason, Thinking About Quality, Progress, Wisdom, and the Deming Philosophy, (Random House, Inc., New York, 1994).

2) B.R.Rich and L.Janos, Skunk Works, (Little Brown and Company, New York, 1995).

3) S. Ozaki, IEEE Particle Accelerator Conference [Accelerator Sci. Technol. 5, 2901(1991)].

4) J.P Hobson and K.M Welch, J. Vac. Sci. Technol. A, 11(4), 1566(1993).

5) L. Dobyns, et al. reference 1, p. 42

6) L. Dobins, et al. reference 1, p. $72 \mathrm{cf}$. 
Figure 1. The Brookhaven National Laboratory Relativistic Heavy Ion Collider (RHIC)

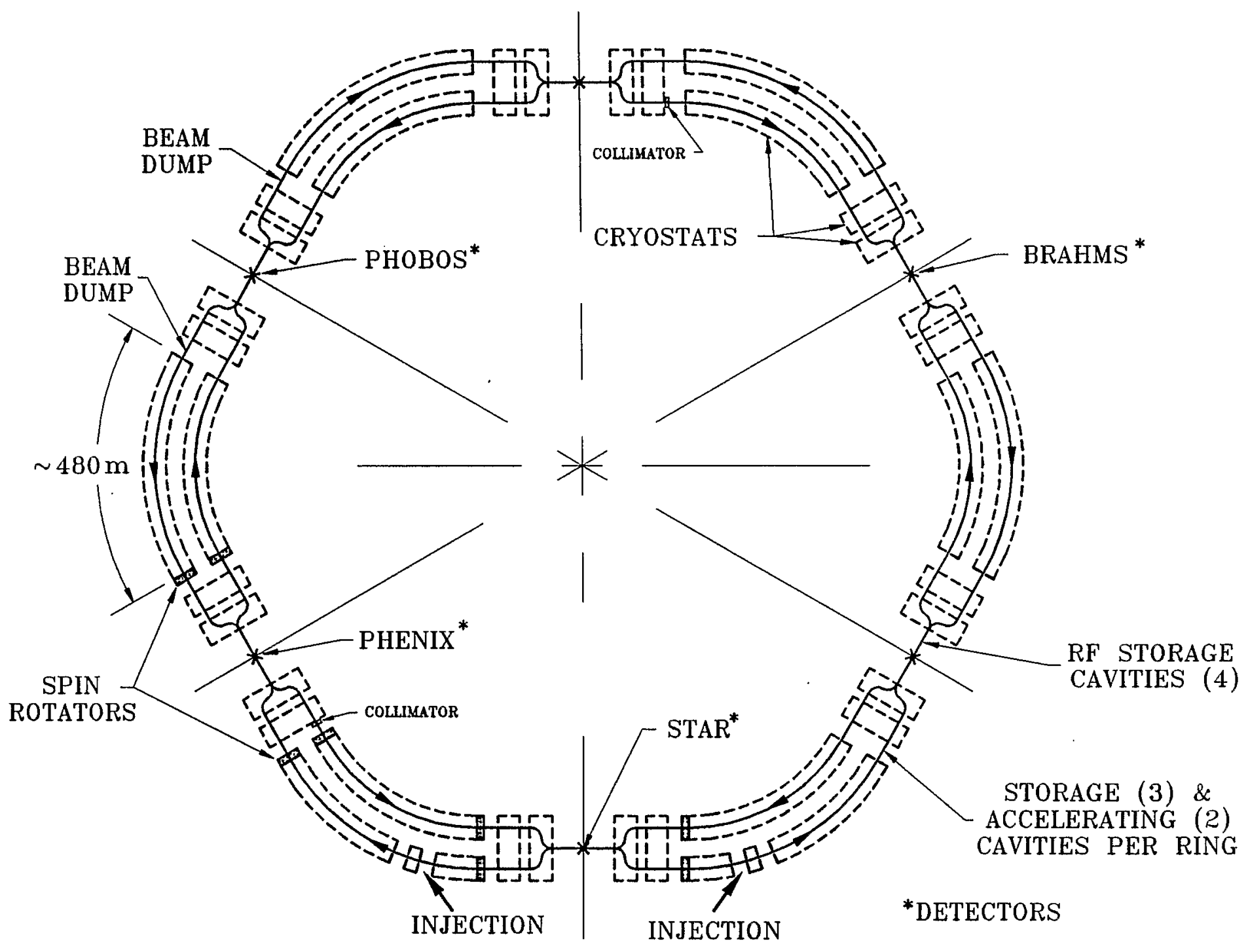


Figure 2. Vacuum Involvement Matrix

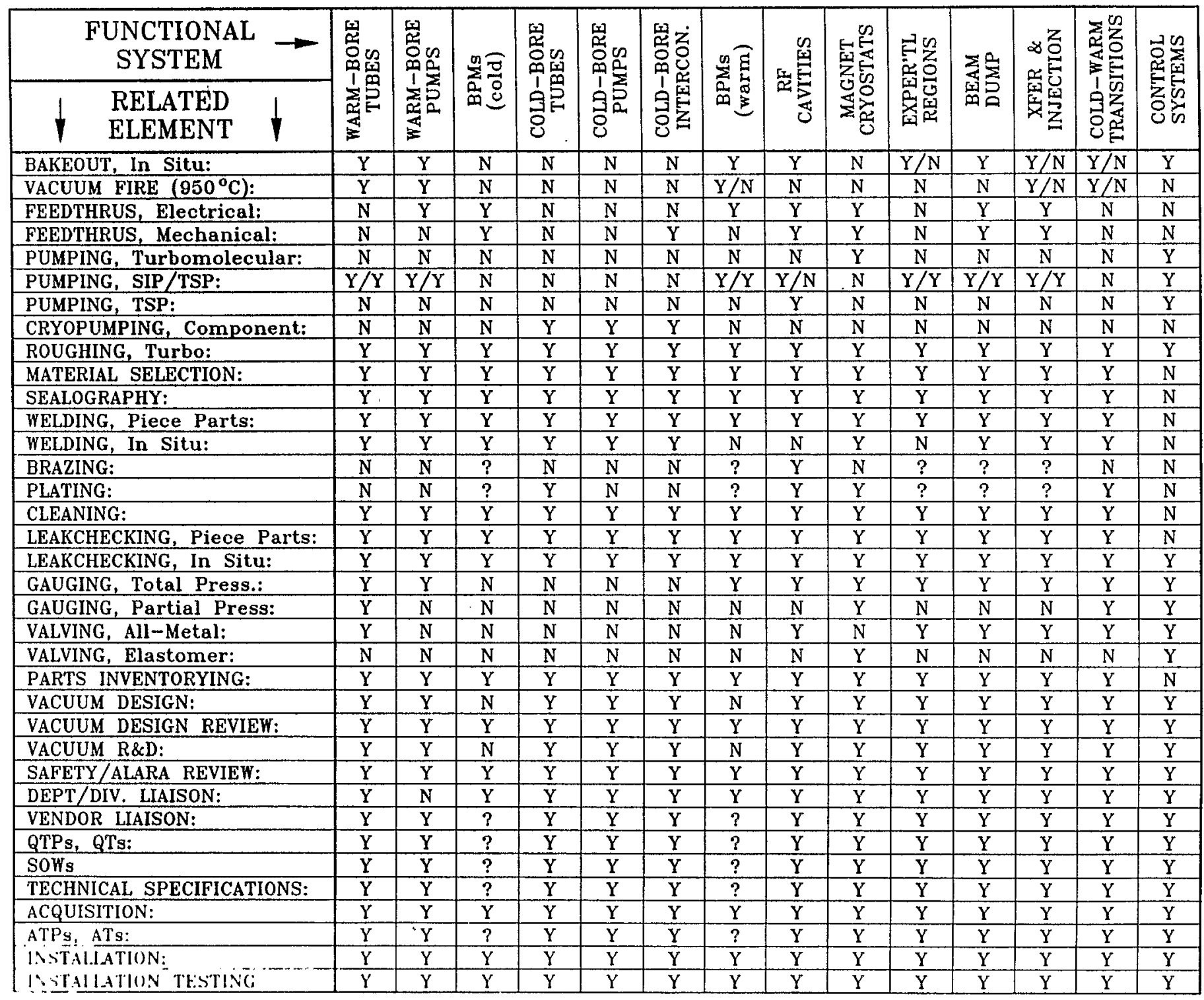


Figure 3. Design Cycle Flow Chart

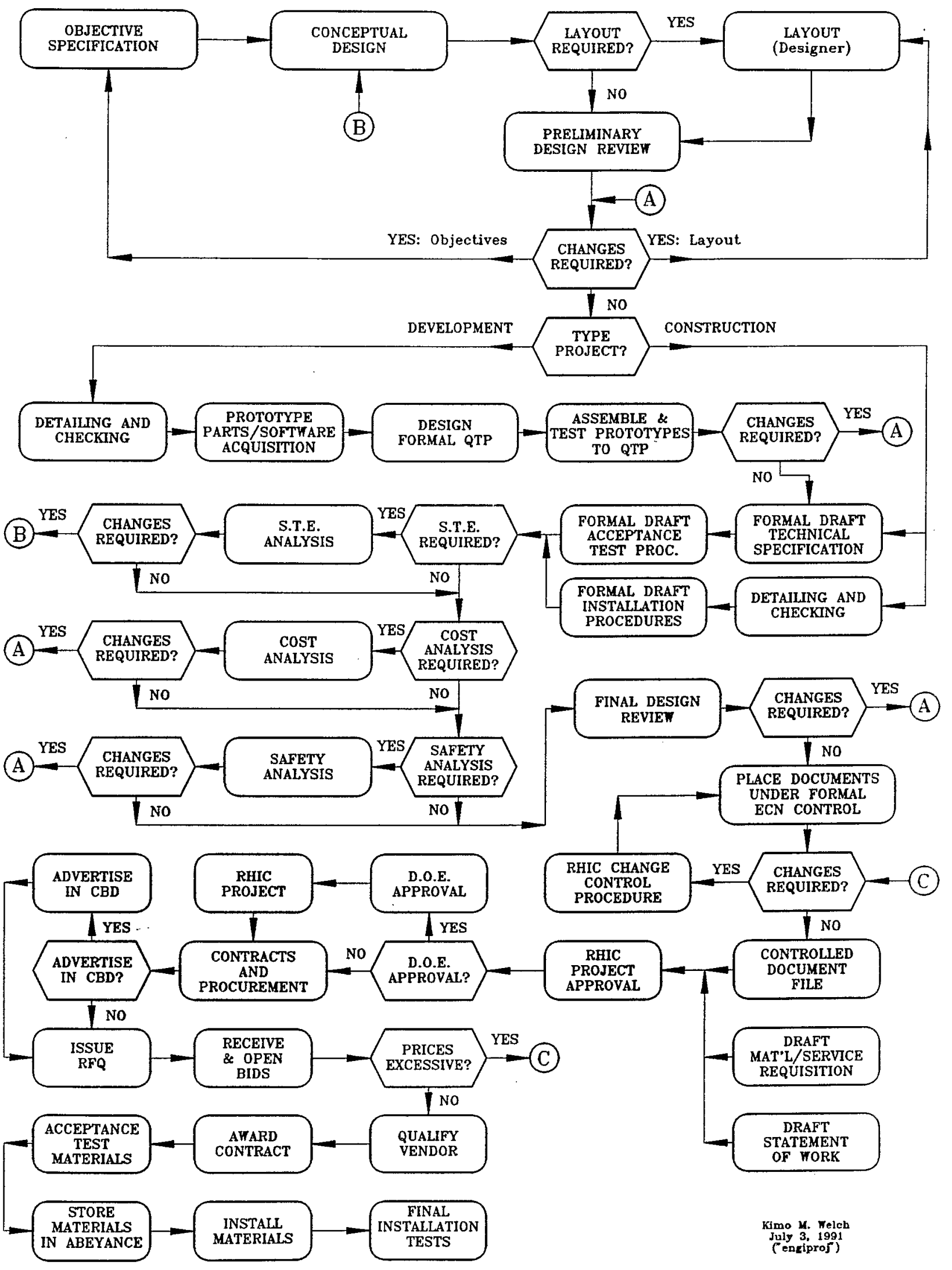


Table I. The Project Cycle Template

\section{PURPOSE \& DEFINITION PHASE}

Objective Specification

Technical Justification

Make Assumptions Known (document)

Conceptual Design

\section{PLANNING PHASE}

Construct WBS

Define Component Quantities \& Cost

Manpower Load Project

Schedule Project

Summarize Program Costs

Present Plan (lobby)

\section{PROPOSAL PHASE}

Generate Preliminary Proposal

Proposal Approval Cycle

Modify Objective Specification

Schedule Project

Manpower Level Project

Prepare and Submit Final Proposal

Final Proposal Approval

Allocate Manpower Resources

Reschedule According to Plan

\section{DESIGN PHASE}

Preliminary Design

Preliminary Design/Cost Review

Resolution of Equipment Residence

Definition of Supporting Utilities

Safety/ALARA Review

Developmental Tests and Equipment

Qualification Test Procedure

Qualification Tests

Acceptance Test Procedure

Prototype Test (if required)

Final Design

Final Design/Cost Review

\section{ACQUISITION PHASE}

Statement of Work

Technical Specifications

Make/Buy Decision

Hold Prebid Conference (?)

Purchasing/Source Liaison

Specification Review/Approval

Acceptance Tests Procedures

Generate Purchasing RFQ/RFP

Advertise in CBD (if $\geq \$ 100 \mathrm{~K}$ )

Issue RFQ or RFP

Receive Quotes

Vendor Qualification

Place Order

Vendor Liaison

First-Article Testing

Modify Design/SOW/Tech. Spec. (?)

Quantity Production

Acceptance Test Equipment/Fixtures

Acceptance Tests

Inventory Production Components

VI. INSTALLATION PHASE

Group Liaison

Final Test 
Table II. Hypothetical Request For Proposal Evaluation Criteria

\begin{tabular}{|l|c|c|c|c|}
\hline TECHNICAL COMPLIANCE: & $\begin{array}{c}\text { POSSIBLE } \\
\%\end{array}$ & $\begin{array}{c}\text { VENDOR } \\
\mathrm{A}^{*}\end{array}$ & $\begin{array}{c}\text { VENDOR } \\
\mathrm{B}^{*}\end{array}$ & $\begin{array}{c}\text { VENDOR } \\
\mathrm{C}^{*}\end{array}$ \\
\hline Meeting BNL Baseline Requirements & 9 & 9 & 7 & 9 \\
\hline Reliability & 9 & 9 & 4 & 6 \\
\hline Maintainability & 9 & 9 & 7 & 7 \\
\hline Component Features Beyond Baseline & 6 & 5 & 0 & 0 \\
\hline Experience in Related Equipment & 3 & 3 & 5 & 5 \\
\hline \multicolumn{1}{|r|}{ Subtotal: } & 36 & 35 & 23 & 27 \\
\hline
\end{tabular}

QUALITY ASSURANCE:

\begin{tabular}{|l|c|c|c|c|}
\hline Established Seller QA Program & 6 & 6 & 4 & 5 \\
\hline Response to BNL Requirements & 6 & 6 & 3 & 6 \\
\hline Quality Assurance Plan Subtotal: & 3 & 3 & 5 & 2 \\
\hline
\end{tabular}

MANAGEMENT CAPABILITY:

\begin{tabular}{|l|c|c|c|c|}
\hline Facilities & 3 & 2 & 2 & 2 \\
\hline Company Profile & 2.4 & 2 & 2 & 2 \\
\hline Organization & 2.4 & 2 & 1 & 1 \\
\hline Subcontractors & 1.2 & 1 & 1 & 1 \\
\hline Subtotal: & 9 & 7 & 6 & 6 \\
ENGINEERING COMPLIANCE TOTAL: & 60 & 57 & 41 & 46 \\
UNIT LIFE CYCLE COST TOTAL: & 40 & 32 & 31 & 39 \\
GRAND TOTAL: & 100 & 89 & 72 & 85
\end{tabular}

* Results as independently assessed by committee of interdepartmental staff. 
Table III. Principles of Operation Used in Configuring RFQ Documentation

1) Ask vendors to do only that which adds value to the product.

2) Never unnecessarily interfere with or create an interruption in a vendor process or procedure.

3) Avoid, unless absolutely necessary, instructing the vendor in how to build the product.

4) Seek clarity in instructing the vendor in what to build.

5) In all cases, if the vendor loses and is unhappy, you will lose and be unhappy.

6) Require that the vendor have some formal QA program in place at the time of bidding (e.g., equivalents of MIL-I-45208 or ISO 9001 Inspection System Requirements).

7) Reserve the option in your RFQ to place orders for first-article items with more than one vendor.

8) Predicate full vendor production turn-on on the technical compliance of firstarticle items delivered for the purpose of vendor qualification.

9) Never ask a vendor to deliver a QA manual before or after bidding. These are seldom read by the vendor, and never read by the customer.

10) Don't bore the vendor with details of all of the tests you may perform at your facility.

11) Always reserve the right to perform any tests, at your own expense, which may be necessary to demonstrate full compliance of the equipment with the contract.

12) Reference only those specifications or procedures in your documentation which are required.

13) Reference only specifications and procedures with which are totally familiar.

14) Formulate an SoW for each acquisition. It describes conditions associated with a specific acquisition.

15) Bear in mind that your SoW is also a $\mathrm{C}^{3}$ vehicle for exchange with Purchasing. 